\title{
Neonatal alloimmune thrombocytopenia and neutropenia associated with maternal human leucocyte antigen antibodies and drug-induced hemolytic anemia
}

\author{
Mengya Sun ${ }^{1}$, Yan Liu ${ }^{1}$, Miao Qin ${ }^{1}$, Ting $\mathrm{Li}^{1}$, and Hong Jiang ${ }^{1}$ \\ ${ }^{1}$ The Affiliated Hospital of Qingdao University
}

February 11, 2021

\begin{abstract}
Fetal and neonatal alloimmune thrombocytopenia (FNAIT) is commonly associated with antibodies against platelet antigens, and alloimmune neonatal neutropenia (ANN) is frequently caused by anti-neutrophil antibodies. Human leukocyte antigen (HLA) antibodies are rarely reported to result in FNAIT or ANN, let alone the combination of FNAIT and ANN. We report here a very unusual case of a first twin pregnancy produced in vitro by donated oocytes where the mother developed markedly elevated HLA antibodies in the absence of anti-platelet or anti-neutrophil antibodies that provoked severe thrombocytopenia and neutropenia in one of the twins. In addition, drug-induced hemolytic anemia (DIHA) that required red blood cell transfusion was detected in this twin. We hypothesize that the complete HLA-incompatible twin pregnancy due to oocyte donation might have contributed to the severity of the clinical manifestations.
\end{abstract}

Neonatal alloimmune thrombocytopenia and neutropenia associated with maternal human leucocyte antigen antibodies and drug-induced hemolytic anemia

Mengya Sun ${ }^{1 *}$, Yan Liu ${ }^{1}$, Miao Qin ${ }^{1}$, Ting Li $^{1}$, Hong Jiang ${ }^{1}$

${ }^{1}$ Department of Neonatology, The Affiliated Hospital of Qingdao University, China

${ }^{*}$ Correspondence to:

Mengya Sun, Department of Neonatology, The Affiliated Hospital of Qingdao University, No 16 of Jiangsu Road, Southern District of Qingdao, Shandong Province ,China, Tel.: 15253201708, Email:

sunmengya616@163.com

Text word count 1615;

Abstract word count: 131;

Brief running title: HLA antibodies caused FNAIT

Key words: fetal and neonatal alloimmune thrombocytopenia; alloimmune neonatal neutropenia; HLA; drug-related hemolytic anemia; neonatal

Tables: 1

Figures: 0

\begin{tabular}{ll}
\hline Abbreviations & Abbreviations \\
FNAIT & fetal and neonatal alloimmune thrombocytopenia
\end{tabular}




\begin{tabular}{ll} 
ANN & alloimmune neonatal neutropenia \\
HLA & human leukocyte antigen \\
DIHA & drug-induced hemolytic anemia \\
HPA & platelet antigen \\
\hline
\end{tabular}

\title{
Neonatal alloimmune thrombocytopenia and neutropenia associated with maternal human leucocyte antigen antibodies and drug-induced hemolytic anemia
}

\begin{abstract}
Fetal and neonatal alloimmune thrombocytopenia (FNAIT) is commonly associated with antibodies against platelet antigens, and alloimmune neonatal neutropenia (ANN) is frequently caused by antineutrophil antibodies. Human leukocyte antigen (HLA) antibodies are rarely reported to result in FNAIT or ANN, let alone the combination of FNAIT and ANN. We report here a very unusual case of a first twin pregnancy produced in vitro by donated oocytes where the mother developed markedly elevated HLA antibodies in the absence of anti-platelet or anti-neutrophil antibodies that provoked severe thrombocytopenia and neutropenia in one of the twins. In addition, drug-induced hemolytic anemia (DIHA) that required red blood cell transfusion was detected in this twin. We hypothesize that the complete HLA-incompatible twin pregnancy due to oocyte donation might have contributed to the severity of the clinical manifestations.
\end{abstract}

Key words: fetal and neonatal alloimmune thrombocytopenia; alloimmune neonatal neutropenia; HLA; drug-related hemolytic anemia; neonatal

\section{Introduction}

Fetal and neonatal alloimmune thrombocytopenia (FNAIT) is an alloimmune disease caused by the incompatibility of fetal and maternal platelet surface antigens during pregnancy. The mother produces immunoglobulin $\mathrm{G}$ ( IgG) through the placenta that acts on fetal or neonatal platelet surface antigens, causing platelet destruction[1]. Numerous platelet antigens and their corresponding antibodies are involved in FNAIT. Severe FNAIT is mostly caused by platelet antigen (HPA) 1a. In neonates with moderately severe to severe thrombocytopenia, petechiae, bruising, and bleeding may be observed. The most serious complication is intracranial hemorrhage[2], and approximately $80 \%$ of intracranial hemorrhage (ICH) occurs in utero[3].

Alloimmune neonatal neutropenia (ANN) also uses a similar mechanism to produce antibodies that act on the neutrophil surface antigens of the fetus or neonatal paternally inherited human neutrophil antigens (HNAs), resulting in neutropenia[4].

Human leukocyte antigen (HLA)-class I antigens are distributed on the surface of platelets and neutrophils, and anti-HLA-class I antibodies can act on platelets and neutrophils to cause FNAIT and ANN[5]. Although HLA antibodies have seldom been reported as an etiology for NAIT and, more rarely, ANN, we report a case of neonatal alloimmune thrombocytopenia and neutropenia caused by human leucocyte antigen-A2, A24 and A68 antibodies without detectable antibodies to HNAs or HPAs. The neonate also had anemia. Finally, we confirmed drug-induced hemolytic anemia caused by anti-piperacillin sodium and tazobactam sodium antibodies.

Case report

A male infant presented with diffuse bruising shortly after delivery. The infant was delivered on September 4, 2020. He was G1P2 with a gestational age of 37 weeks. He was delivered by a cesarean section from a twin pregnancy. The birth weight was $2060 \mathrm{~g}$, and the Apgar score was 10 points for $1 \mathrm{~min}, 5 \mathrm{~min}$, and $10 \mathrm{~min}$. The mother of the infant received oocyte donation (OD) through in vitro fertilization-embryo transfer (the two oocytes were from different donators) due to ovarian failure. The mother's blood type was $\mathrm{B}$ type and $\mathrm{Rh}$ positive, and the father's blood type was $\mathrm{O}$ type and $\mathrm{Rh}$ positive. During pregnancy, the mother had regular check-ups in our hospital and other hospitals. Ultrasound examination at 26 weeks of gestation revealed that the main measurement values of the twins differed by 2-3 weeks, and the right fetus had excessive amniotic fluid. At 37 weeks of gestation, due to twin pregnancy and family members refusing attempted vaginal delivery, cesarean section was performed under epidural anesthesia, and 2 live-born male 
infants were delivered. Both of them had clear amniotic fluid, and the placenta and fetal membrane were delivered intact. The birth weight of infant 1 was $3240 \mathrm{~g}$, and no obvious abnormality was found on physical examination.

The examination results were as follows: temperature 36.0 , heart rate 123 beats/min, breathing rate 43 beats $/ \mathrm{min}$, blood pressure $54 / 26 \mathrm{mmHg}(1 \mathrm{mmHg}=0.133 \mathrm{kPa})$, and weight $2060 \mathrm{~g}$. The infant presented with diffuse bruising on the skin. The complete blood count revealed a white blood cell (WBC) count of $3.29 \times 10^{9} / \mathrm{L}$, absolute neutrophil count of $1.38 \times 10^{9} / \mathrm{L}$, hemoglobin of $164 \mathrm{~g} / \mathrm{L}$, and platelet count of $32 \times 10^{9} / \mathrm{L}$. The infant prothrombin time was $19.20 \mathrm{sec}$, activated partial thromboplastin time was $85.2 \mathrm{sec}$, thrombin time was $19.40 \mathrm{sec}$, and fibrinogen was $1.13 \mathrm{~g} / \mathrm{L}$. Immunoglobulin G (IgG) for Toxoplasma, rubella virus, cytomegalic virus, herpes simplex virus and other pathogens (TORCH) was negative. Blood gas analysis and blood biochemical examination were generally normal.

Infant 2 was admitted to the neonatal intensive care unit (NICU). He was treated with piperacillin sodium and tazobactam sodium for four days, and the blood bacterial culture was negative. He received vitamin K1 and sulphenamide to stop bleeding and cryoprecipitate transfusion twice to supplement fibrinogen. A head ultrasound examination after birth showed no intracranial hemorrhage. During the first month, the infant received a total of 10 doses of IVIG $(1 \mathrm{~g} / \mathrm{kg}$ each). At first, he was transfused with leukocyte-depleted platelets three times $(10 \mathrm{ml} / \mathrm{kg}$ each), but the platelet count did not rise significantly. He then received two treatments with platelets that were irradiated and matched with the infant's mother. The platelet level increased to more than $120 \times 10^{9} / \mathrm{L}$ and finally to approximately $72-97 \times 10^{9} / \mathrm{L}$ before discharge. Neutrophils decreased continuously, and the lowest count was $0.41 \times 10^{9} / \mathrm{L}$ on the 25 th day after birth. Neutrophils can rise temporarily after immunoglobulin, and no granulocyte colony stimulating factor was given during NICU. After treatment with piperacillin sodium and tazobactam sodium for three days, hemoglobin reached $68 \mathrm{~g} / \mathrm{L}$. The Coombs test was positive, the infants were group $\mathrm{O}$ and $\mathrm{RhD}$ positive, and irregular antibodies were negative. Hemolysis caused by acquired antibodies was considered, and we confirmed drug-induced hemolytic anemia caused by anti-piperacillin sodium and tazobactam sodium antibodies with microcolumn gel tests and antihuman globulin tests (MGT-AGTs). Washed red blood cells (WRBCs) were transfused, phototherapy was given, and hemoglobin reached a level of $100 \mathrm{~g} / \mathrm{L}$ on the 10 th day after birth.

For detection of glycoprotein antigenic determinants, anti-HPA antibodies and anti-HNA antibodies were negative in the mother and children, but anti-HLA class I antibodies were positive. Anti-HLAA2, HLA-A24 and HLA-A68 antibodies were detected in the sera of the mother and children and showed strong positivity. To further prove that anti-HLA class I antigen incompatibility is the cause of the anti-HLA antibody, we further tested the HLA class I antigen of the children.

Table 1

HLA class I antibodies present in the mother and HLA A and B typing of the infant.

\begin{tabular}{|c|c|c|c|}
\hline $\begin{array}{l}\text { Class I HLA antibodies } \\
\text { in the mother's serum }\end{array}$ & $\begin{array}{l}\text { Class I HLA antibodies } \\
\text { in the mother's serum }\end{array}$ & $\begin{array}{l}\text { Class I HLA antibodies } \\
\text { in the mother's serum }\end{array}$ & $\begin{array}{l}\text { Class I HLA antibodies } \\
\text { in the mother's serum }\end{array}$ \\
\hline $\begin{array}{l}\text { Strong Positive } \\
\text { (Specificity/Gene Type) }\end{array}$ & MFI & $\begin{array}{l}\text { Positive } \\
\text { (Specificity/Gene Type) }\end{array}$ & MFI \\
\hline $\mathrm{A} 68\left(\mathrm{~A}^{*} 68: 02\right)$ & 14004.46 & $\mathrm{~A} 69(\mathrm{~A} * 69: 01)$ & 9218.72 \\
\hline A68(A*68:01) & 13345.24 & B51(B*51:02) & 5887.53 \\
\hline $\mathrm{A} 2(\mathrm{~A} * 02: 03)$ & 13308.81 & B51(B*51:01) & 5886.43 \\
\hline $\mathrm{A} 24(\mathrm{~A} * 24: 03)$ & 12596.31 & Other $^{\mathrm{a}}$ & \\
\hline $\mathrm{A} 2\left(\mathrm{~A}^{*} 02: 01\right)$ & 11804.51 & & \\
\hline $\mathrm{A} 2(\mathrm{~A} * 02: 06)$ & 11560.24 & & \\
\hline $\mathrm{A} 24(\mathrm{~A} * 24: 02)$ & 11093.89 & & \\
\hline $\begin{array}{l}\text { Class I HLA A and B } \\
\text { antigens in the infant }\end{array}$ & $\begin{array}{l}\text { Class I HLA A and B } \\
\text { antigens in the infant }\end{array}$ & $\begin{array}{l}\text { Class I HLA A and B } \\
\text { antigens in the infant }\end{array}$ & $\begin{array}{l}\text { Class I HLA A and B } \\
\text { antigens in the infant }\end{array}$ \\
\hline Specificity & Type & Type & Type \\
\hline
\end{tabular}




\begin{tabular}{llll}
$\mathrm{A}$ & $\mathrm{A} 2 \mathrm{~A} 68$ & $\mathrm{~A} 2 \mathrm{~A} 68$ & $\mathrm{~A} 2 \mathrm{~A} 68$ \\
$\mathrm{~B}$ & $\mathrm{~B} 51 \mathrm{~B} 55$ & $\mathrm{~B} 51$ B55 & B51 B55 \\
\hline
\end{tabular}

a Other: other specificities with antibodies with MIF higher than 1000: B78, B35, B53, B18, B72, B55, B76, B56, B42, B67, B37 and B62.

Discussion

Anti-HLA antibodies are very common in the serum of pregnant women. Approximately $7 \%-39 \%$ of pregnant women develop anti-HLA antibodies. With the development of technology, $49.3 \%$ of pregnant women with antibodies can be detected with the more sensitive Luminex method[6]. In 18-30\% of pregnant women with multiple pregnancies, anti-HLA antibodies can be detected[7]. While anti-HLA antibodies rarely cause FNAIT or ANN, whether anti-HLA antibodies can be considered the cause of FNAIT/ANN is still controversial. Several theories[8-11] have been postulated to address this discrepancy, such as differential placental absorption, reduced HLA expression on neonatal cells, or binding of alloantibodies to fetal macrophages resulting in inhibition of fetal platelet destruction. However, we report here a very unusual case of a first twin pregnancy produced in vitro fertilization by oocyte and semen donation; the two oocytes were from two donors. HLA-incompatible twin pregnancy due to oocyte donation might have contributed to the high median fluorescence intensity of the mother's antibodies, which were homozygous for class I HLA antigens.

Lashley et al.[12] found that HLA compatibility between donors and recipients could be relevant for the survival of fetal allografts in OD pregnancy, and they observed a significantly higher degree of HLA matching between mothers and children in uncomplicated OD pregnancies than expected, suggesting that HLA compatibility might be beneficial for the development of successful and uncomplicated OD pregnancies. In our case, the two oocytes carrying the HLA genotype may be completely different, which is why infant 1 did not show symptoms of thrombocytopenia. We hypothesize that the HLA between mother and infant 1 is more compatible than that between infant 2. However, the family members refused to test for HLA and antibodies in infant 1 .

Although anti-HLA antibody-mediated FNAIT/ANN is a diagnosis of exclusion and difficult to confirm, the correlation in the case is strong enough. The immunohematological investigation found no anti-HPA and anti-HNA antibodies in the mother's serum or in infant 2. However, we found anti-HLA-A2, anti-HLAA24 and anti-HLA-68 antibodies in both the mother's serum and infant 2. The surfaces of platelets and neutrophils do have the same HLA. We believe that the anti-HLA antibodies may be the reason for FNAIT and ANN in infants. IVIG transfusion is effective in increasing platelet and neutrophil counts.G-CSF was not given in the NICU. The infant's inflammatory indicators were not increased, blood bacterial culture was also negative, and the possibility of infection was not considered.

Dahl[13] showed that thrombocytopenic neonates born to mothers with anti-HLA class I antibodies had a significantly lower birth weight than controls. An increasing level of maternal anti-HLA class I antibodies was linearly and inversely associated with birth weight and placental weight among thrombocytopenic neonates. The birth weight of infant 2 was $2060 \mathrm{~g}$, which is a low birth weight infant (LBWI). However, the birth weight of infant 1 was $3240 \mathrm{~g}$. These results may explain the difference.

Anemia occurred in infant 2 in the NICU. HLA antibody-induced ANN and/or NAIT are characterized by the absence of anemia, as mature erythrocytes do not present HLAs. The direct antiglobulin test (DAT) was positive, and anemia occurred after treatment with piperacillin sodium and tazobactam sodium for three days. Anti-piperacillin sodium and tazobactam sodium antibodies were detected, and hemolysis of the infant was confirmed to be drug-induced hemolytic anemia (DIHA). The direct antiglobulin test (DAT) is invaluable for classifying the cause of RBC destruction as immune or nonimmune[14]. Renard D[15] reported that the incidence of DIHA is approximately only 1 per million/year, but penicillins and cephalosporins are frequent causes of DIHA based on a review of case reports from 2010-2016. This review also examined the probability of DIHA, and several core elements must be taken into account: chronological sequence, 
epidemiological data, objective evidence, and differential diagnosis. Corticosteroids and IVIG are effective in treating anemia.

\section{CONFLICT OF INTEREST}

The authors declare that there is no conflict of interest.

1. Winkelhorst D, Oepkes D. Foetal and neonatal alloimmune thrombocytopenia. Best Pract Res Clin Obstet Gynaecol. 2019 Jul;58:15-27. doi: 10.1016/j.bpobgyn.2019.01.017. Epub 2019 Feb 6. PMID: 30827816.

2. Spencer JA, Burrows RF. Feto-maternal alloimmune thrombocytopenia: a literature review and statistical analysis. Aust N Z J Obstet Gynaecol. 2001 Feb;41(1):45-55. doi: 10.1111/j.1479828x.2001.tb01293.x. PMID: 11284646.

3. Ghevaert C, Campbell K, Walton J, Smith GA, Allen D, Williamson LM, Ouwehand WH, Ranasinghe E. Management and outcome of 200 cases of fetomaternal alloimmune thrombocytopenia. Transfusion. 2007 May;47(5):901-10. doi: 10.1111/j.1537-2995.2007.01208.x. PMID: 17465957.

4. Hagimoto R, Koike K, Sakashita K, Ishida T, Nakazawa Y, Kurokawa Y, Kamijo T, Saito S, Hiraoka A, Kobayashi M, Komiyama A. A possible role for maternal HLA antibody in a case of alloimmune neonatal neutropenia. Transfusion. 2001 May;41(5):615-20. doi: 10.1046/j.1537-2995.2001.41050615.x. PMID: 11346696.

5. Gimferrer I, Teramura G, Gallagher M, Warner P, Ji H, Chabra S. Implication of antibodies against human leukocyte antigen in simultaneous presentation of fetal and neonatal alloimmune thrombocytopenia and neutropenia. Transfus Apher Sci. 2018 Dec;57(6):773-776. doi: 10.1016/j.transci.2018.09.018. Epub 2018 Sep 29. PMID: 30318177.

6. Vilches M, Nieto A. Analysis of Pregnancy-Induced Anti-HLA Antibodies Using Luminex Platform. Transplant Proc. 2015 Nov;47(9):2608-10. doi: 10.1016/j.transproceed.2015.09.032. PMID: 26680049.

7. Regan L, Braude PR, Hill DP. A prospective study of the incidence, time of appearance and significance of anti-paternal lymphocytotoxic antibodies in human pregnancy. Hum Reprod. 1991 Feb;6(2):294-8. doi: 10.1093/oxfordjournals.humrep.a137325. PMID: 2056027.

8. Uenaka M, Morizane M, Tanimura K, Deguchi M, Ebina Y, Hashimoto M, Morioka I, Yamada H. Neonatal Alloimmune Thrombocytopenia: A Report of Four Cases. Kobe J Med Sci. 2019 Mar 5;64(6):E197-E199. PMID: 31327862; PMCID: PMC6668651.

9. King KE, Kao KJ, Bray PF, Casella JF, Blakemore K, Callan NA, Kennedy SD, Kickler TS. The role of HLA antibodies in neonatal thrombocytopenia: a prospective study. Tissue Antigens. 1996 Mar;47(3):206-11. doi: 10.1111/j.1399-0039.1996.tb02542.x. PMID: 8740770.

10. Kristoffersen EK. Placental Fc receptors and the transfer of maternal IgG. Transfus Med Rev. 2000 Jul;14(3):234-43. doi: 10.1053/tm.2000.7393. PMID: 10914418.

11. Taaning E. HLA antibodies and fetomaternal alloimmune thrombocytopenia: myth or meaningful? Transfus Med Rev. 2000 Jul;14(3):275-80. doi: 10.1053/tm.2000.7397. PMID: 10914422.

12. Lashley LE, Haasnoot GW, Spruyt-Gerritse M, Claas FH. Selective advantage of HLA matching in successful uncomplicated oocyte donation pregnancies. J Reprod Immunol. 2015 Nov;112:29-33. doi: 10.1016/j.jri.2015.05.006. Epub 2015 Jun 23. PMID: 26232147.

13. Dahl J, Husebekk A, Acharya G, Flo K, Stuge TB, Skogen B, Straume B, Tiller H. Maternal anti-HLA class I antibodies are associated with reduced birth weight in thrombocytopenic neonates. J Reprod Immunol. 2016 Feb;113:27-34. doi: 10.1016/j.jri.2015.10.003. Epub 2015 Oct 29. PMID: 26547815.

14. Zantek ND, Koepsell SA, Tharp DR Jr, Cohn CS. The direct antiglobulin test: a critical step in the evaluation of hemolysis. Am J Hematol. 2012 Jul;87(7):707-9. doi: 10.1002/ajh.23218. Epub 2012 May 6. PMID: 22566278.

15. Renard D, Rosselet A. Drug-induced hemolytic anemia: Pharmacological aspects. Transfus Clin Biol. 2017 Sep;24(3):110-114. doi: 10.1016/j.tracli.2017.05.013. Epub 2017 Jun 23. PMID: 28648734.

\section{Hosted file}

Table.pdf available at https://authorea.com/users/395130/articles/508457-neonatal-alloimmune- 
thrombocytopenia-and-neutropenia-associated-with-maternal-human-leucocyte-antigenantibodies-and-drug-induced-hemolytic-anemia 